\title{
Relationship between the expression of Notch1 and EZH2 and the prognosis of breast invasive ductal carcinoma
}

\author{
L. Zhao, Q.Y. Zhang, X. Luan, X. Huang, S. Zhao and H. Zhao \\ Department of Medical Oncology, The Tumor Hospital of Harbin Medical University, \\ Harbin, China \\ Corresponding author: Q.Y. Zhang \\ E-mail: doctor0818@126.com \\ Genet. Mol. Res. 15 (1): gmr.15017464 \\ Received August 18, 2015 \\ Accepted December 3, 2015 \\ Published March 18, 2016 \\ DOI http://dx.doi.org/10.4238/gmr.15017464
}

ABSTRACT. We determined whether the coexpression of Notch1 and $\mathrm{EZH} 2$ influences the progression and prognosis of breast invasive ductal carcinoma. Using the $\chi^{2}$ test, a significant difference was found between high and low expression of Notch1 in terms of lymph node, hormone receptor, and p53 expression $(P<0.05)$. Moreover, a significant difference was found between high and low expression of EZH2 in terms of tumor size, histologic grade, hormone receptor, and expression of Ki67 ( $P<$ 0.05). Using Pearson correlation analysis, we found a significant positive correlation between Notch1 and EZH2 expression in the tissue samples of breast invasive ductal carcinoma $(P=0.038)$. High Notch1 and EZH2 expression was associated with poor progression-free survival compared with low expression $\left(P_{\text {Notch } 1}=0.000,40.3\right.$ vs 48.9 months; $P_{E Z H 2}=0.000$, 40.2 vs 49.9 months). Moreover, we found that high Notch1 and EZH2 expression was associated with poor overall survival compared with low expression $\left(P_{\text {Notch } 1}=0.000,51.2\right.$ vs 56.2 months; $P_{\text {EZH } 2}=0.002,51.7$ vs 56.4 months). In conclusion, Notch1 and EZH2 coexpression contributes to the progression and prognosis of breast invasive ductal carcinoma.

Key words: Notch1; EZH2; Invasive ductal carcinoma; Prognosis 


\section{INTRODUCTION}

Breast cancer is one of the most common malignancies in women (Siegel et al., 2012). In Chinese women, it is the most common cancer and the third most common cause of cancerrelated death (Smith et al., 2015). The number of women suffering from breast cancer in China is increasing, while the number of deaths is expected to decrease (Wong et al., 2015). Although improvements in early detection and treatment have reduced breast cancer mortality rates in recent years, prevention and therapy remain a major public health concern (Lang et al., 2015). Thus, identification and determination of new genes/pathways involved in breast cancer carcinogenesis will help in the development of better disease prognoses following treatment of breast cancer.

The Notch gene family encodes a group of evolutionarily conserved transmembrane receptors (Notch1-4) that are expressed on the cell surface as heterodimers. Notch signaling has been implicated in the self-renewal of stem cells or progenitor cells isolated from mammary glands (Dontu et al., 2003, 2004). Notch1 plays a role in human mammary tumorigenesis (Zardawi et al., 2010; Wang et al., 2011); it is reported that Notch1 is highly expressed in human primary breast ductal carcinoma and is activated by the Ras signaling pathway (Stier et al., 2002).

Enhancer of zeste homolog $2(\mathrm{EZH} 2)$ is involved in controlling embryonic development and cell proliferation (Jacobs and van Lohuizen, 2002; Cao and Zhang 2004). EZH2 is a highly conserved histone methyltransferase that targets lysine 27 of histone H3 and methylated H3$\mathrm{K} 27$, and is correlated with the silencing of genes for differentiation (Kirmizis et al., 2004). The expression of EZH2 is associated with proliferative and more aggressive tumor phenotypes, and thus contributes to the development of carcinogenesis (Varambally et al., 2002; Bachmann et al., 2006). Some researchers have reported that EZH2 plays a critical role in the development and prognosis of breast cancer (Bachmann et al., 2006), but none has reported the association in a Chinese population. Moreover, to date no one has reported an association between the expression of Notch1 and EZH2 and the development and prognosis of breast invasive ductal carcinoma. In this study, we attempted to determine whether the coexpression of Notch1 and EZH2 influences the progression and prognosis of breast invasive ductal carcinoma.

\section{MATERIAL AND METHODS}

\section{Patients and tissue samples}

Between 2003 and 2006, a total of 171 patients with breast invasive ductal carcinoma were recruited from the Third Affiliated Hospital of Harbin Medical University. All patients received postoperative adjuvant therapy. Patients who underwent preoperative radiochemotherapy were excluded from the study.

Thirty-two samples of normal tissue adjacent to the carcinoma were collected and used as controls during the same period. Tissue sections exhibiting - or + Her2 immunohistochemical staining were considered negative for Her2 expression. For cases with ++ staining, further in situ fluorescence hybridization was carried out to determine expression levels, as described in a previous study (Galgano et al., 2006).

Overall survival (OS) was calculated at the time of operation until death or last known date alive. Progression-free survival (PFS) was calculated the time of operation until disease progression or death. All patients provided written informed consent prior to study enrollment. This 
study was reviewed and approved by the Ethics Committee of the Third Affiliated Hospital of Harbin Medical University.

\section{Immunohistochemistry}

Tissue microarrays were prepared according to standard procedures, and Notch1 and EZH2 were immunostained separately. For the immunohistochemical assays, 4- $\mu m$-thick sections cut from paraffin-embedded tissue blocks were dewaxed in xylene and dehydrated in graded ethanol. These sections were then placed in 1X ethylenediaminetetraacetic acid buffer for 20 min and incubated in methanol with $3 \%$ hydrogen peroxide for $30 \mathrm{~min}$. After rehydration with phosphatebuffered saline, the sections were incubated with rabbit polyclonal antibody against human Notch1 (1:100 dilution, Abcam, USA) or EZH2 primary antibody (1:100 dilution, Cell Signaling, USA) for 2 $\mathrm{h}$ at room temperature. The sections were then washed three times in phosphate-buffered saline and reacted with horseradish peroxidase-polymer anti-rabbit lgG (1:100, Solomon Biotechnology Co., Ltd., China) for $1 \mathrm{~h}$. Reactivity was developed in 3,3'-diaminobenzidine chromogen solution. The digital images of the five representative visual fields from slides that were positive for Notch1 and EZH2 (400X) were analyzed using the Image-Pro Plus 6.0 software (Media Cybernetics, Inc., Bethesda, USA).

The immunohistochemically stained sections were independently evaluated by two pathologists. Four grades were used to evaluate the staining intensity: negative (0), weak (1), medium (2), and strong (3). The degree of staining and the percentage of positive cells were scored as follows: $0,<10 \% ; 1,10-25 \% ; 2,26-50 \% ; 3,50-75 \%$; and 4, $\geq 76 \%$. Discrepancies were resolved by consensus between the two pathologists. The grades were multiplied to determine an $\mathrm{H}$-score according to the method described in a previous study (Galgano et al., 2006). Negative or weak expression with scores between 0 and 3 was considered low expression, and strong expression (scores $\geq 4$ ) was considered low or high expression.

\section{Statistical analysis}

Continuous variables are reported as means $\pm S D$, and categorical variables are shown by number $(\mathrm{N})$ of subjects (\%). The association between the expression level of Notch1 and EZH2 and the clinicopathological characteristics of the patients was assessed using the $\chi^{2}$ or Fisher exact tests. Correlation between Notch1 and EZH2 expression was evaluated by Pearson coefficient analyses. The Cox proportional hazards regression model was used to analyze the factors for the PFS and OS. The Kaplan-Meier method was used to plot the PFS and OS curves. The SPSS $^{\circledR}$ statistical package, version 11.0 (SPSS Inc., Chicago, IL, USA) for Windows ${ }^{\circledR}$ was used for statistical analyses. All $P$ values were two-tailed, and a difference was considered statistically significant when $\mathrm{P}<0.05$.

\section{RESULTS}

The correlation between Notch1 and EZH2 expression and clinical and pathological characteristics of patients with breast invasive ductal carcinoma are shown in Table 1. The median patient age of the patients with breast invasive ductal carcinoma was 50 years (range, 29-68 years). Of the 171 tumor samples, Notch1 and EZH2 were expressed at high levels in 85 (50\%) 
and $93(54 \%)$ samples, respectively. Using the $\chi^{2}$ test, a significant difference was found between high and low expression of Notch1 in terms of lymph node, hormone receptor, and expression of p53 ( $P$ < 0.05). Moreover, a significant difference was found between high and low expression of $\mathrm{EZH} 2$ in terms of tumor size, histologic grade, hormone receptor, and expression of Ki67 $(\mathrm{P}<0.05)$.

\begin{tabular}{|c|c|c|c|c|c|c|}
\hline \multirow[t]{2}{*}{ Parameters } & \multicolumn{3}{|c|}{ Notch1 } & \multicolumn{3}{|c|}{$\mathrm{EZH} 2$} \\
\hline & High (\%) & Low (\%) & $P$ value & High (\%) & Low (\%) & $\mathrm{P}$ value \\
\hline \multicolumn{7}{|l|}{ Age } \\
\hline$\leq 49$ & $44(52 \%)$ & $34(40 \%)$ & \multirow[t]{2}{*}{0.126} & $43(46 \%)$ & $35(45 \%)$ & \multirow{2}{*}{0.879} \\
\hline$>49$ & $41(48 \%)$ & $52(60 \%)$ & & $50(54 \%)$ & $43(55 \%)$ & \\
\hline \multicolumn{7}{|l|}{ Tumor size } \\
\hline$\leq 2 \mathrm{~cm}$ & $44(52 \%)$ & $41(48 \%)$ & \multirow{2}{*}{0.647} & $39(42 \%)$ & $46(59 \%)$ & \multirow{2}{*}{0.032} \\
\hline$>2 \mathrm{~cm}$ & $41(48 \%)$ & $45(52 \%)$ & & $54(58 \%)$ & $32(41 \%)$ & \\
\hline \multicolumn{7}{|l|}{ Histologic grade } \\
\hline$I+I I$ & $46(54 \%)$ & $52(63 \%)$ & \multirow{2}{*}{0.441} & $46(50 \%)$ & $52(67 \%)$ & \multirow{2}{*}{0.03} \\
\hline III & $39(46 \%)$ & $34(37 \%)$ & & $47(50 \%)$ & $26(33 \%)$ & \\
\hline \multicolumn{7}{|l|}{ Lymph node } \\
\hline Negative & $30(35 \%)$ & $44(51 \%)$ & \multirow{2}{*}{0.045} & $38(41 \%)$ & $36(46 \%)$ & \multirow{2}{*}{0.537} \\
\hline Positive & $55(65 \%)$ & $42(49 \%)$ & & $55(59 \%)$ & $42(54 \%)$ & \\
\hline \multicolumn{7}{|l|}{ Hormone receptor } \\
\hline ER(-) & $47(51 \%)$ & $28(36 \%)$ & \multirow{2}{*}{0.038} & $60(65 \%)$ & $33(42 \%)$ & \multirow{2}{*}{0.005} \\
\hline$E R(+)$ & $46(49 \%)$ & $50(64 \%)$ & & $33(35 \%)$ & $45(58 \%)$ & \\
\hline PR(-) & $48(56 \%)$ & $46(53 \%)$ & \multirow{2}{*}{0.759} & $59(63 \%)$ & $35(45 \%)$ & \multirow{2}{*}{0.02} \\
\hline $\mathrm{PR}(+)$ & $37(44 \%)$ & $40(47 \%)$ & & $34(37 \%)$ & $43(55 \%)$ & \\
\hline Her2/neu (-) & $49(58 \%)$ & $65(77 \%)$ & \multirow[b]{2}{*}{0.015} & $55(59 \%)$ & $59(76 \%)$ & \multirow[b]{2}{*}{0.024} \\
\hline Her2/neu (+) & $36(42 \%)$ & $21(23 \%)$ & & $38(41 \%)$ & $19(24 \%)$ & \\
\hline \multicolumn{7}{|l|}{ Pathologic stage } \\
\hline$|+| \mid$ & $62(73 \%)$ & $65(70 \%)$ & \multirow{2}{*}{0.729} & $66(71 \%)$ & $61(78 \%)$ & \multirow{2}{*}{0.298} \\
\hline III & $23(27 \%)$ & $21(30 \%)$ & & $27(29 \%)$ & $17(22 \%)$ & \\
\hline P53(-) & $36(42 \%)$ & $50(58 \%)$ & \multirow[b]{2}{*}{0.047} & $46(49 \%)$ & $40(51 \%)$ & \multirow[b]{2}{*}{0.878} \\
\hline P53(+) & $49(58 \%)$ & $36(42 \%)$ & & $47(51 \%)$ & $38(49 \%)$ & \\
\hline Ki67(-) & $45(53 \%)$ & $44(51 \%)$ & \multirow{2}{*}{0.879} & $39(42 \%)$ & $50(64 \%)$ & \multirow{2}{*}{0.006} \\
\hline Ki67(+) & $40(47 \%)$ & $42(49 \%)$ & & $54(58 \%)$ & $28(36 \%)$ & \\
\hline \multicolumn{7}{|l|}{ Menopausal status } \\
\hline Pre-menopausal & $26(31 \%)$ & $35(41 \%)$ & & $34(37 \%)$ & $27(35 \%)$ & \\
\hline Post-menopausal & $59(69 \%)$ & $51(59 \%)$ & 0.202 & $59(63 \%)$ & $51(65 \%)$ & 0.873 \\
\hline
\end{tabular}

The correlation between EZH2 and Notch1 expression is shown in Table 2. Using Pearson correlation analysis, we found a significant positive correlation between Notch1 and EZH2 expression and breast invasive ductal carcinoma in the tissue samples $(P=0.038)$.

Table 2. Correlation between EZH2 and Notch1 expression.

\begin{tabular}{l|c|c|c|c}
\hline \multirow{2}{*}{ Notch1 } & \multicolumn{2}{|c|}{ EZH2 } & Pearson correlation & P value \\
\cline { 2 - 5 } & Negative $(\mathrm{N})$ & Positive $(\mathrm{N})$ & 0.159 & 0.038 \\
\hline Negative $(\mathrm{N})$ & 46 & 40 & & \\
\hline Positive $(\mathrm{N})$ & 32 & 53 & & \\
\hline
\end{tabular}

The role of high Notch1 and EZH2 expression in PFS and OS was evaluated using KaplanMeier analysis. High Notch1 and EZH2 expression was associated with poor PFS compared with low expression $\left(P_{\text {Notch1 }}=0.000,40.3\right.$ vs 48.9 months; $P_{E Z H 2}=0.000,40.2$ vs 49.9 months, Figure 1). Moreover, we found that high Notch1 and EZH2 expression was associated with poor OS compared with low expression $\left(P_{\text {Notch1 }}=0.000,51.2\right.$ vs 56.2 months; $P_{\text {EZH } 2}=0.002,51.7$ vs 56.4 months, Figure 2). 

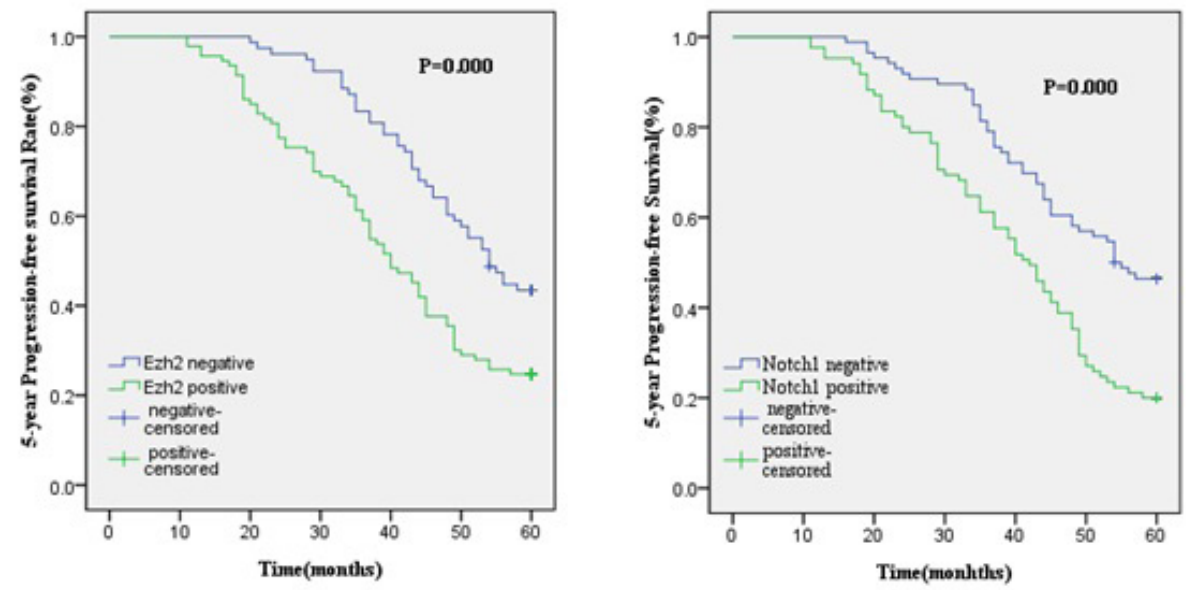

Figure 1. Correlation between Notch1 and EZH2 expression and progression-free survival.
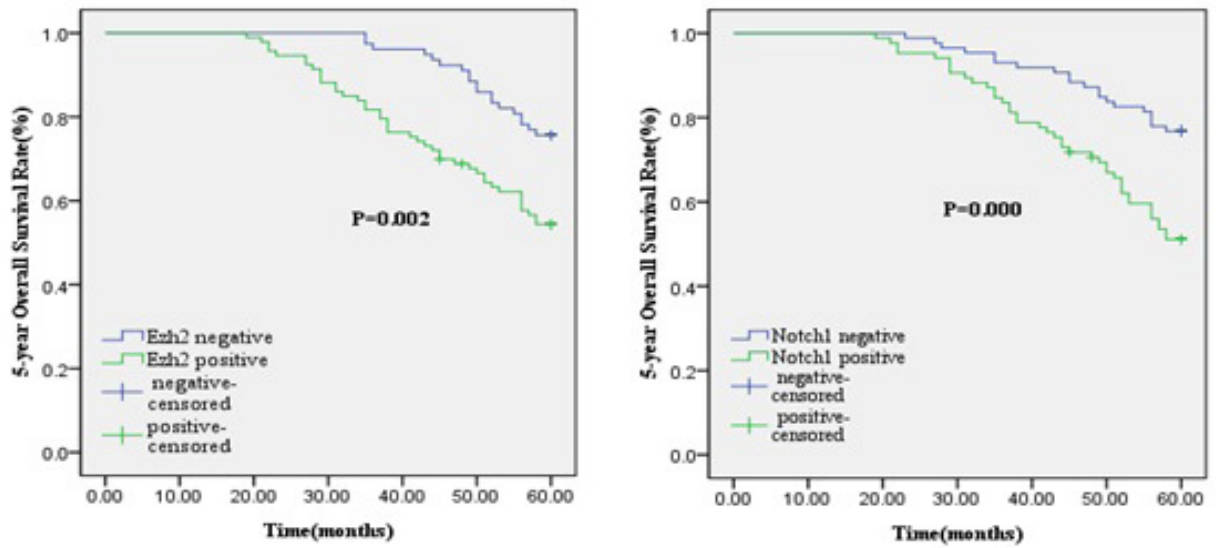

Figure 2. Correlation between Notch1 and EZH2 expression and overall survival.

Using the Cox proportional hazards regression model, we found that $\mathrm{ER}(+)$ was negatively associated with disease recurrence and metastasis for patients with breast invasive ductal carcinoma $(\mathrm{HR}=0.546,95 \% \mathrm{Cl}=0.361-0.826)$ (Table 3). The Her-2(+), high Notch1, and $\mathrm{EZH} 2$ expression levels were associated with a higher risk of disease recurrence or metastasis for patients with breast invasive ductal carcinoma [for Her-2(+), $\mathrm{HR}=2.028,95 \% \mathrm{Cl}=1.342-$ 3.066; for high Notch1 expression, $\mathrm{HR}=1.559,95 \% \mathrm{Cl}=1.050-2.315$; and for high $\mathrm{EZH} 2$ expression, $\mathrm{HR}=1.514,95 \% \mathrm{Cl}=1.028-2.229]$. Moreover, $\mathrm{ER}(+)$ was associated with lower risk of OS compared with ER(-) (HR $=0.229,95 \% \mathrm{Cl}=0.116-0.450)$. High Notch1 expression was associated with higher risk of death compared with low Notch1 expression $(\mathrm{HR}=1.848,95 \% \mathrm{Cl}$ $=1.054-3.237)$. 
Table 3. Multivariate analysis of prognostic factors for patients with breast invasive ductal carcinoma.

\begin{tabular}{|c|c|c|c|}
\hline Parameters & Hazard ratio & $P$ value & $95 \% \mathrm{Cl}$ \\
\hline \multicolumn{4}{|l|}{ PFS } \\
\hline $\mathrm{ER}(+)$ & 0.546 & 0.004 & $0.361-0.826$ \\
\hline Her-2(+) & 2.028 & 0.001 & $1.342-3.066$ \\
\hline High Notch1 expression & 1.559 & 0.028 & $1.050-2.315$ \\
\hline High EZH2 expression & 1.514 & 0.036 & $1.028-2.229$ \\
\hline \multicolumn{4}{|l|}{ OS } \\
\hline $\mathrm{ER}(+)$ & 0.229 & 0.000 & $0.116-0.450$ \\
\hline Her-2(+) & 1.059 & 0.830 & $0.626-1.794$ \\
\hline High Notch1 expression & 1.848 & 0.032 & $1.054-3.237$ \\
\hline High EZH2 expression & 1.638 & 0.084 & $0.936-2.867$ \\
\hline
\end{tabular}

PFS = progression-free survival; OS = overall survival.

\section{DISCUSSION}

The identification of shared genetic determinants for the early prophylaxis and treatment of breast cancer is the premise emerging from the results of accumulative association studies. In the present study, we found that there was a significant positive correlation between Notch1 and EZH2 expression and breast invasive ductal carcinoma. High Notch1 and EZH2 expression levels were associated with a higher risk of disease recurrence or metastasis in patients with breast invasive ductal carcinoma, and high Notch1 expression was associated with higher risk of death in patients with that affliction. These results indicate that Notch1 and EZH2 coexpression contributes to the progression and prognosis of breast invasive ductal carcinoma.

It has been reported that Notch1 plays a predominantly oncogenic role in tumorigenesis, including that of breast cancer (Reedijk et al., 2005; Klinakis et al., 2006; Alimirah et al., 2007), and Notch1 small hairpin RNA can reduce cellular growth and macro- and micrometastasis (McGowan et al., 2011). Anti-Notch1 monoclonal antibodies can delay tumor recurrence and enhance the antitumor efficacy of chemotherapy (Qiu et al., 2013). The authors of previous studies have reported that expression of Notch1 is associated with a prognosis of breast cancer (Ma et al., 2011; Yao et al., 2011; Zhu et al., 2013; Cao et al., 2014; Yuan et al., 2015). Yuan et al. (2015) conducted a study in a Chinese population and reported that Notch inhibitors play a role in blocking the early progression of ductal carcinoma in situ; they also reported the outcomes of clinical trials for Notch1-targeting therapeutics. Ma et al. (2011) suggested Notch1 was associated with the clinical parameters of breast cancer patients. Yao et al. (2011) reported that Notch1 is correlated with the prognosis of breast cancer patients. Our study also found an association between the expression of Notch1 and progression and prognosis of breast invasive ductal carcinoma, which corroborates previous studies.

$\mathrm{EZH} 2$ is a crucial component of polycomb repressive complex 2. Overexpression of EZH2 is an important driver of tumor development and is often correlated with human cancer progression and poor prognosis (Sauvageau and Sauvageau, 2010). The forced expression of EZH2 in cell lines can increase proliferation and oncogenic capacity (Piunti and Pasini, 2011). Additionally, reducing $\mathrm{EZH} 2$ expression and $\mathrm{EZH} 2$ degradation inhibits cell growth and reduces tumor formation in cancers (Qiu et al., 2013). Ntziachristos et al. (2012) reported that Notch1 interacts with EZH2 to control gene expression and cell transformation in T-cell acute lymphoblastic leukemia. The authors of a previous meta-analysis reported that EZH2 is a putative factor in the progression of breast cancer, and overexpression of $\mathrm{EZH} 2$ is distinctly correlated with poor survival of breast cancer (Wang et al., 2015). In this study, we found that EZH2 is associated with the progression of breast invasive ductal carcinoma, which is correlated to the expression of Notch1. 
In conclusion, our study suggests that Notch1 and EZH2 may be promising biomarkers and future therapeutic targets for breast invasive ductal carcinoma. Future studies with larger sample sizes are required to confirm the role of Notch1 and EZH2 in the progression and prognosis of breast invasive ductal carcinoma.

\section{Conflicts of interest}

The authors declare no conflict of interest.

\section{ACKNOWLEDGMENTS}

This experiment was performed in the Oncobiology Key Laboratory of the Heilongjiang Common Institution of Higher Learning. We thank all participants and the Department of Oncology, The Third Affiliated Hospital of Harbin Medical University, Harbin, China.

\section{REFERENCES}

Alimirah F, Panchanathan R, Davis FJ, Chen J, et al. (2007). Restoration of p53 expression in human cancer cell lines upregulates the expression of Notch1: implications for cancer cell fate determination after genotoxic stress. Neoplasia 9: 427-434. http://dx.doi.org/10.1593/neo.07211

Bachmann IM, Halvorsen OJ, Collett K, Stefansson IM, et al. (2006). EZH2 expression is associated with high proliferation rate and aggressive tumor subgroups in cutaneous melanoma and cancers of the endometrium, prostate, and breast. J. Clin. Oncol. 24: 268-273. http://dx.doi.org/10.1200/JCO.2005.01.5180

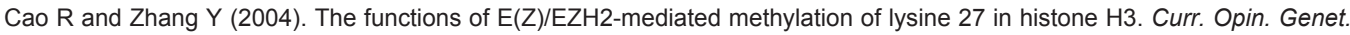
Dev. 14: 155-164. http://dx.doi.org/10.1016/j.gde.2004.02.001

Cao YW, Li WQ, Wan GX, Li YX, et al. (2014). Correlation and prognostic value of SIRT1 and Notch1 signaling in breast cancer. J. Exp. Clin. Cancer Res. 33: 97. http://dx.doi.org/10.1186/s13046-014-0097-2

Dontu G, Al-Hajj M, Abdallah WM, Clarke MF, et al. (2003). Stem cells in normal breast development and breast cancer. Cell Prolif. 36 (Suppl 1): 59-72. http://dx.doi.org/10.1046/j.1365-2184.36.s.1.6.x

Dontu G, Jackson KW, McNicholas E, Kawamura MJ, et al. (2004). Role of Notch signaling in cell-fate determination of human mammary stem/progenitor cells. Breast Cancer Res. 6: R605-R615. http://dx.doi.org/10.1186/bcr920

Galgano MT, Hampton GM and Frierson HF, Jr. (2006). Comprehensive analysis of HE4 expression in normal and malignant human tissues. Mod. Pathol. 19: 847-853.

Jacobs JJ and van Lohuizen M (2002). Polycomb repression: from cellular memory to cellular proliferation and cancer. Biochim. Biophys. Acta 1602: 151-161.

Kirmizis A, Bartley SM, Kuzmichev A, Margueron R, et al. (2004). Silencing of human polycomb target genes is associated with methylation of histone H3 Lys 27. Genes Dev. 18: 1592-1605. http://dx.doi.org/10.1101/gad.1200204

Klinakis A, Szabolcs M, Politi K, Kiaris H, et al. (2006). Myc is a Notch1 transcriptional target and a requisite for Notch1-induced mammary tumorigenesis in mice. Proc. Natl. Acad. Sci. USA 103: 9262-9267. http://dx.doi.org/10.1073/pnas.0603371103

Lang JE, Wecsler JS, Press MF and Tripathy D (2015). Molecular markers for breast cancer diagnosis, prognosis and targeted therapy. J. Surg. Oncol. 111: 81-90. http://dx.doi.org/10.1002/jso.23732

Ma D, Dong X, Zang S, Ma R, et al. (2011). Aberrant expression and clinical correlation of Notch signaling molecules in breast cancer of Chinese population. Asia Pac. J. Clin. Oncol. 7: 385-391. http://dx.doi.org/10.1111/j.1743-7563.2011.01433.x

McGowan PM, Simedrea C, Ribot EJ, Foster PJ, et al. (2011). Notch1 inhibition alters the CD44hi/CD24lo population and reduces the formation of brain metastases from breast cancer. Mol. Cancer Res. 9: 834-844. http://dx.doi.org/10.1158/1541-7786. MCR-10-0457

Ntziachristos P, Tsirigos A, Van Vlierberghe P, Nedjic J, et al. (2012). Genetic inactivation of the polycomb repressive complex 2 in T cell acute lymphoblastic leukemia. Nat. Med. 18: 298-301. http://dx.doi.org/10.1038/nm.2651

Piunti A and Pasini D (2011). Epigenetic factors in cancer development: polycomb group proteins. Future Oncol. 7: 57-75. http://dx.doi.org/10.2217/fon.10.157

Qiu M, Peng Q, Jiang I, Carroll C, et al. (2013). Specific inhibition of Notch1 signaling enhances the antitumor efficacy of chemotherapy in triple negative breast cancer through reduction of cancer stem cells. Cancer Lett. 328: 261-270. http:// 
dx.doi.org/10.1016/j.canlet.2012.09.023

Reedijk M, Odorcic S, Chang L, Zhang H, et al. (2005). High-level coexpression of JAG1 and NOTCH1 is observed in human breast cancer and is associated with poor overall survival. Cancer Res. 65: 8530-8537. http://dx.doi.org/10.1158/00085472.CAN-05-1069

Sauvageau M and Sauvageau G (2010). Polycomb group proteins: multi-faceted regulators of somatic stem cells and cancer. Cell Stem Cell 7: 299-313. http://dx.doi.org/10.1016/j.stem.2010.08.002

Siegel R, Naishadham D and Jemal A (2012). Cancer statistics, 2012. CA Cancer J. Clin. 62: 10-29. http://dx.doi.org/10.3322/ caac.20138

Smith RA, Manassaram-Baptiste D, Brooks D, Doroshenk M, et al. (2015). Cancer screening in the United States, 2015: a review of current American cancer society guidelines and current issues in cancer screening. CA Cancer J. Clin. 65: 3054. http://dx.doi.org/10.3322/caac. 21261

Stier S, Cheng T, Dombkowski D, Carlesso N, et al. (2002). Notch1 activation increases hematopoietic stem cell self-renewal in vivo and favors lymphoid over myeloid lineage outcome. Blood 99: 2369-2378. http://dx.doi.org/10.1182/blood.V99.7.2369

Varambally S, Dhanasekaran SM, Zhou M, Barrette TR, et al. (2002). The polycomb group protein EZH2 is involved in progression of prostate cancer. Nature 419: 624-629. http://dx.doi.org/10.1038/nature01075

Wang J, Fu L, Gu F and Ma Y (2011). Notch1 is involved in migration and invasion of human breast cancer cells. Oncol. Rep. 26: 1295-1303.

Wang X, Hu B, Shen H, Zhou H, et al. (2015). Clinical and prognostic relevance of EZH2 in breast cancer: A meta-analysis. Biomed. Pharmacother. 75: 218-225. http://dx.doi.org/10.1016/j.biopha.2015.07.038

Wong IO, Schooling CM, Cowling BJ and Leung GM (2015). Breast cancer incidence and mortality in a transitioning Chinese population: current and future trends. Br. J. Cancer 112: 167-170. http://dx.doi.org/10.1038/bjc.2014.532

Yao K, Rizzo P, Rajan P, Albain K, et al. (2011). Notch-1 and notch-4 receptors as prognostic markers in breast cancer. Int. J. Surg. Pathol. 19: 607-613. http://dx.doi.org/10.1177/1066896910362080

Yuan X, Zhang M, Wu H, Xu H, et al. (2015). Expression of Notch1 Correlates with Breast Cancer Progression and Prognosis. PLoS One 10: e0131689. http://dx.doi.org/10.1371/journal.pone.0131689

Zardawi SJ, Zardawi I, McNeil CM, Millar EK, et al. (2010). High Notch1 protein expression is an early event in breast cancer development and is associated with the HER-2 molecular subtype. Histopathology 56: 286-296. http://dx.doi.org/10.1111/ i.1365-2559.2009.03475.x

Zhu H, Bhaijee F, Ishaq N, Pepper DJ, et al. (2013). Correlation of Notch1, pAKT and nuclear NF-kB expression in triple negative breast cancer. Am. J. Cancer Res. 3: 230-239. 